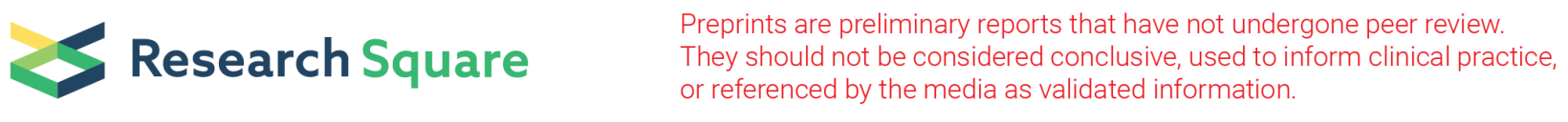

\title{
Assessment of Eco-Economic Effects of Urban Water System Connectivity Project
}

Cuimei Lv

Zhengzhou University

Huali Liao

Zhengzhou University

Minghua Ling ( $\sim$ 366357398@qq.com)

Zhengzhou University

Zening Wu

Zhengzhou University

Denghua Yan

China Institute of Water Resources and Hydropower Research Department of Water Resources

\section{Research Article}

Keywords: Emergy theory, Urban water system connectivity project, Ecological economic effect, Composition system, Quantification

Posted Date: December 17th, 2021

DOI: https://doi.org/10.21203/rs.3.rs-1081748/v1

License: (c) (i) This work is licensed under a Creative Commons Attribution 4.0 International License. Read Full License

Version of Record: A version of this preprint was published at Environmental Science and Pollution Research on March 14th, 2022. See the published version at https://doi.org/10.1007/s11356-022-19552-w. 


\section{Abstract}

As one of the large ecological infrastructures, urban water system connectivity project is an important part of urban ecosystem construction. It has a variety of effects, such as conserving biodiversity, enriching urban landscape and increasing land value. It is helpful for the scientific planning and construction of the project to systematically evaluate the effects. However, due to the complex and various effects of urban water system connectivity project, there is no complete effect system and quantitative method. In this paper, the composition and mechanism of positive and negative effects of ecological economics of urban water system connectivity project were deeply analyzed to improve the composition system of eco-economic effects. At the same time, the emergy theory was used to put forward the quantification method of ecoeconomic effect system. Taking the urban water system connectivity project in Xuchang as an example, it's ecological, social and economic effects were evaluated. The result showed that the average eco-economic effect of the project is 57.8 million dollars/year. Economic effect and ecological effect are significant, accounting for $88.83 \%$ and $9.77 \%$ of total effect, respectively. The former is mainly due to land value increment, and the latter is principally owing to biodiversity conservation. It showed that the water system connectivity project in Xuchang can promote the economic development of the surrounding areas and create a good ecological environment, which will bring huge eco-economic effect to the region.

\section{Introduction}

River system is the carrier of water resources, the component of ecological environment and the foundation of economic and social development (Olaj et al. 2012). Urban development cannot be separated from the river and lake ecosystem. As an urban open space, urban water system connectivity project has eco-economic effects, such as improving water quality, providing recreational places and increasing the value of real estate (Anderson and West 2006; Brander and Koetse 2011). It can provide good resources and ecological environment for urban development. In recent years, a large number of urban water system connectivity projects have been built all over the world, such as Boston Park system in the United States, the restoration of Bishan-Ang Mao Kio Park and Kallang River in Singapore, and the Wuhan Dadong Lake ecological water network project in China. The advantages and disadvantages of the urban water system connectivity project can be objectively assessed by analyzing and quantifying the ecological, social and economic effects of the project, so as to carry out scientific and reasonable planning and construction of the project and realize the sustainable development of the city (Grizzetti et al. 2016).

A large number of studies by scholars have shown that the construction of urban water system will produce a series of effects on the urban eco-economic system. Park et al. (2017) simulated and analyzed urban microclimate change due to the variation of wind flow and temperature assuming situations before and after urban river restoration, indicating that this project can improve urban microclimate and comfort level. Through water diversion tests and water quantity and quality models, Cui et al. (2017) found that the improvement of water system structural connectivity improves water transfer efficiency and water quality improvement. Yan and Li (2010) conducted a numerical simulation analysis on the water quality monitoring points of Wuhan Dadong Lake after the implementation of the water network connectivity project, and found that the pollution indicators had been improved. Asakawa et al. (2004) investigated community residents' perception of river corridors through questionnaire survey, and concluded that leisure and entertainment are highly correlated with residents' preferences. Using the Hedonic model, Chen (2016) found that urban water system governance has an important impact on the housing price. Wang et al. (2011) pointed out that the Xi'an urban water system connectivity project has ecological function, cultural function and entertainment function.

For the assessment of eco-economic effect of urban water system, scholars mostly adopt the economic method. MartínezPaz et al. (2014) used conditional value to evaluate the annual benefits of the environmental restoration of the Segura River flowing through the city of Murcia in Spain. Everard et al. (2011) used an alternative market approach to quantify the benefits of the Mayes Brook River in terms of provisioning, regulatory, culture and supporting services. Mourato et al. (2005) used the willingness to pay method to evaluate the non-market benefits of the Thames River in London using. Wu et

Page 2/18 
al. (2005) evaluated the ecosystem service value of the comprehensive regulation of Zhangjiabang River in Shanghai by the contingent valuation method. Zhang (2017) analyzed the ecosystem services of urban water system in Zhengzhou, and quantified their effects by using market value method and travel cost method. Xue et al. (2018) used the equivalent factor method to evaluate the culture, supply, regulation and support services of the water system ecological corridor in central Beijing.

Based on the research above, the positive effects of urban water system were analyzed and calculated, but the negative effects were not considered. At the same time, a complete effect system has not been constructed. In addition, these studies mostly use the external-effect internalization method to monetize non-market commodities such as ecological effect and social effect, but this method is difficult to accurately measure their real value (Steinhorst et al. 2015). Emergy theory takes emergy as the benchmark, and integrates the ecological economic effect into a common non-monetary unit solar emergy joules(sej) to quantify (Liu et al. 2019). Thus, the unified measurement of ecological economic system can be realized. Therefore, based on the functions of urban water system connectivity project, this paper analyzed the composition system and mechanism of the positive and negative effect of project from three aspects of ecology, society and economy. the emergy theory was introduced to put forward the emergy evaluation method of ecological economic effect system of project. It provided a new idea for quantitative analysis of urban water system connectivity project. At the same time, this paper taken the Xuchang urban water system connectivity project as an example to evaluate the ecoeconomic effects produced by the project, which provided a basis for the value evaluation, planning and management of the project.

\section{Methods And Materials}

\subsection{Study Area}

Xuchang City $\left(\mathrm{N} 33^{\circ} 42^{\prime}-34^{\circ} 24^{\prime}\right.$, E $\left.113^{\circ} 03^{\prime}-114^{\circ} 19^{\prime}\right)$ is located in the central part of Henan Province, China, covering an area of $4996 \mathrm{~km}^{2}$, with an average altitude of $72.8 \mathrm{~m}$. The annual average temperature of Xuchang is between $14.3 \sim 14.6^{\circ} \mathrm{C}$, and the annual average precipitation over the years is between $671.1 \mathrm{~mm} \sim 736 \mathrm{~mm}$. The rivers in Xuchang belong to the Shaying River basin of the Huaihe River basin. There are 4 rivers with the catchment area more than $1000 \mathrm{~km}^{2}$, including Beiru River, Yinghe River, Shuangji River, and Qingyi River. There are 19 rivers with the catchment area more than $100 \mathrm{~km}^{2}$.

In May 2013, Xuchang municipal government carried out the water system connectivity project in Weidu District and Jian'an District of Xuchang City. The Qingyi River, Qingni River, Yunniang river, Yinma River and other channels were connected. Furong Lake, Luming Lake, Baling Lake and the Eastern Wetland Park were built. The project realized the connection of rivers and lakes, forming a complete ecological water system(Fig. 1,2). After the completion of the urban water system connectivity project, the water surface area has reached $433.33 \mathrm{hm}^{2}$, and the green area has increased to $433.33 \mathrm{hm}^{2}$.

\subsection{Methodology}

\subsubsection{Emergy Theory}

Emergy theory was established by Odom H.T., a famous American system ecologist. He defined the emergy as the amount of energy in one kind of flow or storage that contains another kind of energy. Based on emergy analysis, energy from different sources and properties can be uniformly converted into the same standard for measurement and analysis. The unified quantification of energy flow, logistics flow, money flow and other ecological flow is realized. Any energy is directly or indirectly derived from solar energy. Therefore, solar emergy is taken as the benchmark, other types of energy are converted into solar emergy through the solar transformity for unified analysis (Odum 1996). The formula is as follows:

$E M=\tau \times B(1)$ 
In the above formula, EM is emergy (sej), $\tau$ is the solar transformity (sej/ $\mathrm{J}$ or sej/g), $B$ is the energy or material quality ( $\mathrm{J}$ or g).

According to emergy analysis method, the relationship between solar emergy and currency can be established through emergy/currency ratio (EDR). The emergy/currency ratio of a country (or region) is equal to the ratio of the total annual energy input in the economic system of the country (or region) to the current gross domestic product. EDR can convert the emergy of the ecological economic system into equivalent market currency value. Thus, the problem that it is difficult to uniformly measure the income of natural resources and the monetary income of economic society is solved (Lan et al. 2002).

It can be seen that emergy method is not a substitute for currency to measure economic behavior, but a perfection of traditional economic methods ( $\mathrm{Lv}$ et al. 2021). In this paper, the eco-economic effects of urban water system connectivity project were fully considered, and a relatively scientific and perfect effect quantification system was established by using emergy method.

\subsection{2 the composition of eco-economic effect}

Water is an inexhaustible driving force for the development of human society and plays an irreplaceable role in the development of urban economy. As the carrier of water resources, the construction of water system connectivity project will inevitably produce a variety of effects. According to the analysis, the project increases the urban water surface area, which leads to local climate improvement, enhances biodiversity by connecting the bodies of water. It can also transport sediment, purify water quality, protect the ecological environment health, so the construction of the project has ecological effect. The project enriches the urban landscape, increases the recreational places for residents, and strengthens the flood control ability. The research related to the project is also increasing gradually. The construction of the project promotes the social development and has social effect. The urban waterfront formed by the project has become an important position in the economic development of the city. The construction of the project enhances the value of the surrounding land and has economic effect. However, the construction of the project will make the river channelized, which will lead to the negative effect on ecology such as serious water pollution and service function degradation, and the daily maintenance of the project will also bring corresponding negative economic effect. To sum up, the positive and negative effects of ecology, society and economy brought by the project were considered synthetically, and a relatively complete system of ecoeconomic effect was constructed (Fig. 3).

\subsubsection{Emergy Assessment Method}

Before the completion of the project, the urban water system itself had eco-economic effects, such as regulating climate and providing recreational places. The construction of the project changed the size of these effects. In this paper, the difference in the effects size between before and after the completion of the project is taken as the eco-economic effects produced by the project.

$E M=E M_{2}-E M_{1}(2)$

where $E M$ is the effect of project (sej), $E M_{1}$ is the effect before completion of the project (sej), $E M_{2}$ is the effect after completion of the project (sej).

\subsubsection{Emergy Assessment Method of Ecological Effect}

(1) Climate Regulation Effect

The urban water system connectivity project increases the urban water surface area, water evaporation increases the air humidity, lowers the local temperature of the city, and relieves the urban heat island effect. In addition, the green space 
surrounding the project consumes ground radiant heat in the city through a large amount of water transpiration. Therefore, it can be considered that the evaporation energy of water reflects the climatic regulation ability of the project. The formula for calculating the climatic regulation effect is as follows:

$E M_{q}=L \times G \times \tau_{s}(3)$

$L=2507.4-2.39 t(4)$

where $E M_{q}$ is the climate regulation effect (sej), $L$ is the latent heat of evaporation $(\mathrm{J} / \mathrm{g}), \mathrm{G}$ is the amount of evaporated water $(\mathrm{g}), \tau_{s}$ is the solar transformity of steam (sej/J).

(2) Biodiversity Conservation Effect

Urban water system connectivity project is an important habitat and ecological corridor for supporting urban biodiversity, which can provide a variety of habitats for animals and plants in and around urban water bodies. As an important connecting channel of urban ecosystem network, project enhances the connectivity of ecological network system, which is conducive to energy flow and material exchange among biological species. Green Spaces around the river system also provide breeding grounds for birds, amphibians and reptiles, thus helping to maintain the overall biodiversity of the city. Biodiversity conservation effect can be expressed by the number of species and the area of biological activity in the region, and the calculation formula is as follows:

$E M_{B}=\tau_{b} \times N \times R(5)$

where $E M_{B}$ is the biodiversity conservation effect (sej), $\tau_{b}$ is the average emergy transformity of biological species, which is $1.26 \times 10^{25} \mathrm{sej} /$ species (Wen et al. 2005), $N$ is the total number of biological species within the scope of the project, $R$ is the proportion of biological active area to global area, in which the surface area of the earth is $5.21 \times 10^{10} \mathrm{hm}^{2}$.

\section{(3) Sediment Transportation Effect}

The water system connectivity project connects independent lakes, rivers and channels, enhancing the flow of water bodies. Sediment transportation depends on the flowing water, and the total energy of the flow at any cross-section is equal to the sum of potential energy and kinetic energy (Wu et al. 2019). Sediment transportation effect is realized by working on suspended and bedding sediment in water body. Therefore, the basic formula can be established according to the energy principle:

$E_{M D}=(P E+K E) \times\left(\theta_{1}+\theta_{2}\right) \times \tau_{d}(6)$

where $E M_{D}$ is the sediment transportation effect (sej), $P_{E}$ is the variation of potential energy $(\mathrm{j}), K_{E}$ is the variation of kinetic energy $(j), \theta_{1}$ is the bedload energy transfer coefficient, $\theta_{2}$ is the suspended load energy transfer coefficient, $\tau_{d}$ is the solar transformity of river water energy (sej/j).

\section{(4) Water Purification Effect}

Water can purify pollutants through a series of physical and biochemical reactions such as natural dilution, adsorption, diffusion and oxidation. The self-purification function of water body ensures the recycling of all kinds of substances in the river ecosystem, effectively prevents the pollution caused by excessive accumulation of substances, and purifies and improves the water environment. The water system connectivity project integrates the water system in the region, promotes water circulation, speeds up water exchange, turns stagnant water into living water, and improves the pollutant purification capacity of the water system. Finally, the water environment is improved. The purification effect of water can be expressed by quantifying the amount of pollutants naturally degraded in water. The formula is as follows:

Page 5/18 
$E M_{p}=\sum_{p=1}^{n} f \times m_{p} \times \tau_{p}(7)$

where $E M_{p}$ is the water purification effect (sej), $f$ is the self-purification coefficient of water body, $m_{p}$ is the amount of pollutants $(\mathrm{g}), \tau_{p}$ is the solar transformity of each pollutant $(\mathrm{sej} / \mathrm{g})$.

(5) Negative Effect on The Ecology

The construction of project needs the excavation of artificial channels and drainage channels, usually also needs to solidify the revetment and riverbed. The channelization of water system destroys the hydrological connection between water body and the outside world, and changes the structure and function of natural rivers. When a large amount of waste water is discharged into the river, the channeling of the water system speeds up the destruction of the ecosystem. Water pollution is the main damage of water ecosystem caused by channelization, and water pollution changes the solar transformity of water. Therefore, it's effect can be quantified according to the solar transformity of water body before and after discharge and sewage discharge quantity. The calculation formula is as follows:

$E M_{w}=\left(\tau_{w a}-\tau_{w b}\right) \times W_{w}(8)$

where $E M_{w}$ is negative effect on the ecology (sej), $\tau_{w a}$ is the solar transformity before pollution (sej/ $\left.\mathrm{m}^{3}\right), \tau_{w b}$ is the solar transformity after pollution $\left(\mathrm{sej} / \mathrm{m}^{3}\right), W_{w}$ is the sewage discharge quantity $\left(\mathrm{m}^{3}\right)$.

\subsubsection{Emergy Assessment method of Social Effect}

\section{(1) Flood Regulation Effect}

The acceleration of urbanization leads to the increase of impervious underlying area. As a result, the rainwater runoff becomes more and more concentrated, the flood peak time of the river is advanced, the confluence time is shortened, and the pressure of flood control of the river is intensified. The implementation of the project can connect different water systems to play a combined effect, and increase the river and lake storage capacity by restoring or building water system connection channels. When the flood occurs, we can turn the harm into the benefit by flood retention and peak staggered regulation which are realized through reasonably regulating the dam and sluice in the urban river system. The project will enhance the local flood control and drainage functions of urban water systems, ensure the safety of people's lives and property, and play a huge flood control effect. The effect can be calculated by the emergy of the flood storage volume. The formula is as follows:

$E M_{f}=\tau \times W_{f}(9)$

where $E M_{f}$ is the flood regulation effect (sej), $\tau_{f}$ represents the solar transformity of the corresponding water body (sej $/ \mathrm{m}^{3}$ ), $W_{f}$ is the flood storage volume in the study area $\left(\mathrm{m}^{3}\right)$.

(2) Landscape and Recreation Effect

People's leisure activities cannot be separated from the natural landscape, and the green space around the urban water system is generated by the combination of the natural ecosystem and the artificial construction system. With the construction of urban water system connectivity project, a variety of urban ecological landscape can be presented, which provides open places for residents to jog, relax, picnic and other recreational activities. It brings good experience and feeling to residents, so that residents' happiness is improved. The landscape and recreation effect of the project can be quantified by referring to the equivalent factor method proposed by Xie et al. $(2003,2015)$, which is obtained by multiplying the recreation value per unit water area by the area of the river system. The formula is as follows:

$E M_{e}=E D R \times V_{e} \times A(10)$ 
where $E M_{e}$ is the landscape and recreation effect (sej), $V_{e}$ is the value equivalent of landscape and recreation per unit water area $\left(¥ / \mathrm{hm}^{2}\right), A$ is the water area $\left(\mathrm{hm}^{2}\right)$.

(3) Scientific Research Effect

Urban water ecosystem has the characteristics of complex and diverse ecological environment and rich species resources, and is an important research area of ecology, hydrology, water resources, environmental engineering, aquatic biology and fishery resources. Therefore, the project of urban water system connectivity has important scientific research and cultural value. The effect of scientific research is quantified by the emergy value of related academic papers. The formula is as follows:

$E M_{s}=T \times 6 \times \tau_{s}(11)$

where $E M_{s}$ is the scientific research effect (sej), $T$ is the number of academic papers published during the study period, each academic paper is counted as 6 pages, $\tau_{s}$ is the solar transformity of academic papers, which is $3.39 \times 10^{15} \mathrm{sej} / \mathrm{P}$ calculated by Meillaud et al. (2005).

\subsubsection{Emergy Assessment Method of Economic Effect}

\section{(1) Land Value Increment Effect}

With the improvement of people's living standards, people's demand is constantly improving, and more and more attention is paid to the surrounding environmental quality and infrastructure supporting conditions. With beautiful scenery and fresh air around the urban water system connectivity project, it can get closer to nature and improve people's quality of life. Because people yearn for green life and visual beauty, the demand for housing around the project increases, and the commercial value also increases accordingly. According to the research of Liang et al. (2010), after comprehensive treatment of urban rivers, $31.43 \%$ of the land value increment effect are generated by the urban water system. The calculation formula is as follows:

$E M_{l}=Q \times 31.43 \% \times E D R(12)$

where $E M_{l}$ is the land value increment effect (sej), $Q$ is the total increment of land ( $\left.¥\right)$.

\section{(2) Negative Effect of Maintenance}

In order to ensure the healthy and sustainable development of urban water system, it is necessary to invest a lot of manpower, material resources and financial resources in the construction and management of river courses, including cleaning work of river surface and river bank, inspection and improvement of water quality, dredging of river, etc. Increasing the financial expenditure of the city is the negative effect of the urban water system connectivity project, which can be calculated by the emergy consumption of the invested labor and equipment. The calculation formula is as follows:

$E M_{g}=G \times E D R(13)$

where $E M_{g}$ is the negative effect of maintenance (sej), $G$ is the annual expenditure of project maintenance (¥).

\section{Results And Discussion}

Xuchang urban water system connectivity project was constructed from 2013 to 2015, so 2010 2012 (before the completion of the project) and 2016 2018 (after the completion of the project) were selected as the research period. According to the emergy calculation method mentioned above, the emergy currency ratio of Xuchang City was calculated, and the eco-economic effects of the project were assessed. The original data are mainly from Henan Statistical Bureau 
(HSB 2010-2012,2016-2018), Xuchang Statistical Bureau (XSB 2010-2012,2016-2018) and Henan Water Conservancy Bureau (HWCB 2010-2012,2016-2018). The solar transformities mainly refer to the results of Lan. The emergy currency ratio (EDR) of Xuchang City was calculated based on the method of Lv (2009). Other data sources are identified below.

\subsection{Assessment of Ecological Effect of Urban Water System Connectivity Project in Xuchang \\ 3.1.1 Climate Regulation Effect}

According to the emergy assessment method given above, the climate regulation effect of urban water system connectivity project in Xuchang was quantified. The annual evaporation depth was obtained from the evaluation report of current water resources in Qingyi River Basin of Xuchang section. Based on Formula (3) and Formula (4), the emergy of climate regulation effect can be obtained (Table 1).

Table 1

Calculation results of climate regulation effect of project in Xuchang

\begin{tabular}{|llllllll|}
\hline Items & Units & $\mathbf{2 0 1 0}$ & $\mathbf{2 0 1 1}$ & $\mathbf{2 0 1 2}$ & $\mathbf{2 0 1 6}$ & $\mathbf{2 0 1 7}$ & $\mathbf{2 0 1 8}$ \\
\hline Annual mean temperature & ${ }^{\circ} \mathrm{C}$ & 13.8 & 13.4 & 13.7 & 15.4 & 15.4 & 15.0 \\
\hline Latent heat of evaporation & $\mathrm{j} / \mathrm{g}$ & 2474.42 & 2475.37 & 2474.66 & 2470.59 & 2470.59 & 2471.55 \\
\hline Annual evaporation degree & $\mathrm{mm}$ & 1188.75 & 1097.70 & 726.15 & 944.40 & 1113.60 & 771.60 \\
\hline Annual evaporation & $10^{12} \mathrm{~g}$ & 3.67 & 3.38 & 2.24 & 4.09 & 4.83 & 3.34 \\
\hline Energy of vaporization & $10^{16} \mathrm{j}$ & 0.91 & 0.84 & 0.55 & 1.01 & 1.19 & 0.83 \\
\hline Solar transformity of steam & $\mathrm{sej} / \mathrm{j}$ & 12.20 & 12.20 & 12.20 & 12.20 & 12.20 & 12.20 \\
\hline Climate regulation effect & $10^{17} \mathrm{sej}$ & 1.11 & 1.02 & 0.68 & 1.23 & 1.45 & 1.01 \\
\hline
\end{tabular}

\subsubsection{Biodiversity Conservation Effect}

According to a species survey in Qingyi River Basin, the species number did not change after the project was completed, but the area of biological activity changed. In the basin of Qingyi River, 111 species of planktonic and periphytic algae, 18 species of macrophyte, 42 species of zooplankton, 22 species of zoobeanthos, and 33 species of fish were found (Hao 2018). The total number of species is 226 . Based on Formula (5), the biodiversity conservation effect can be calculated (Table 2).

Table 2

Calculation results of biodiversity conservation effect of project in Xuchang

\begin{tabular}{|llll|}
\hline Items & Units & $\mathbf{2 0 1 0 ~ 2 0 1 2}$ & 2016 2018 \\
\hline Species & species & 226 & 226 \\
\hline Solar transformity of species & $10^{25}$ sej/species & 1.26 & 1.26 \\
\hline Species active area & $\mathrm{hm}^{2}$ & 308.33 & 433.33 \\
\hline Surface area of earth & $10^{10} \mathrm{hm}^{2}$ & 5.21 & 5.21 \\
\hline Biodiversity conservation effect & $10^{19}$ sej & 1.69 & 2.37 \\
\hline
\end{tabular}

\subsubsection{Water Purification Effect}


According to Water Resources Bulletin of Xuchang City, the main water pollutants in the study area are ammonia nitrogen $\left(\mathrm{NH}_{3}-\mathrm{N}\right)$ and chemical oxygen demand (COD). In Qingyi River Basin, the degradation coefficient of COD and $\mathrm{NH}_{3}-\mathrm{N}_{\text {are }}$ $0.15 / d$ and $0.18 / d$ respectively (Zhang et al. 2015). Based on Formula (7), the water purification effect can be calculated (Table 3)

Table 3

Calculation results of water purification effect of project in Xuchang

\begin{tabular}{|llllllll|}
\hline Items & Units & $\mathbf{2 0 1 0}$ & $\mathbf{2 0 1 1}$ & $\mathbf{2 0 1 2}$ & $\mathbf{2 0 1 6}$ & $\mathbf{2 0 1 7}$ & $\mathbf{2 0 1 8}$ \\
\hline Discharge of $\mathrm{NH}_{3}-\mathrm{N}$ & $10^{8} \mathrm{~g}$ & 2.19 & 2.11 & 1.99 & 2.59 & 2.06 & 1.78 \\
\hline Solar transformity of $\mathrm{NH}_{3}-\mathrm{N}$ & $10^{9} \mathrm{sej} / \mathrm{g}$ & 7.0 & 7.0 & 7.0 & 7.0 & 7.0 & 7.0 \\
\hline Self-purification coefficient of $\mathrm{NH}_{3}-\mathrm{N}$ & $/ \mathrm{d}$ & 0.18 & 0.18 & 0.18 & 0.18 & 0.18 & 0.18 \\
\hline Discharge of COD & $10^{9} \mathrm{~g}$ & 0.94 & 1.54 & 1.51 & 1.72 & 1.51 & 1.41 \\
\hline Solar transformity of COD & $10^{6} \mathrm{sej} / \mathrm{j}$ & 4.84 & 4.84 & 4.84 & 4.84 & 4.84 & 4.84 \\
\hline Self-purification coefficient of COD & $/ \mathrm{d}$ & 0.15 & 0.15 & 0.15 & 0.15 & 0.15 & 0.15 \\
\hline Water purification effect & $10^{18}$ sej & 5.13 & 8.24 & 8.07 & 9.21 & 8.04 & 7.50 \\
\hline * $\mathrm{NH}_{3}$ - $\mathrm{N}$ Solar transformity reference Carey (2011), COD Solar transformity reference Sun et al. (2019). \\
\hline
\end{tabular}

\subsubsection{Negative Effect on The Ecology}

The solar transformity of water body before pollution was expressed by the solar transformity of surface water in Xuchang, which can be obtained by the ratio of the annual emergy of precipitation and the chemical energy in the catchment (Lv 2009). Based on Formula (8), the negative effect on the ecology can be calculated (Table 4).

Table 4

Calculation results of environmental deterioration effect of project in Xuchang

\begin{tabular}{|llllllll|}
\hline Items & Units & $\mathbf{2 0 1 0}$ & $\mathbf{2 0 1 1}$ & $\mathbf{2 0 1 2}$ & $\mathbf{2 0 1 6}$ & $\mathbf{2 0 1 7}$ & $\mathbf{2 0 1 8}$ \\
\hline Sewage discharge & $10^{6} \mathrm{~m}^{3}$ & 4.34 & 4.63 & 4.78 & 6.68 & 5.93 & 5.91 \\
\hline Solar transformity of water before pollution & $10^{11} \mathrm{sej} / \mathrm{m}^{3}$ & 5.93 & 5.93 & 5.93 & 5.93 & 5.93 & 5.93 \\
\hline Solar transformity of water after pollution & $10^{11} \mathrm{sej} / \mathrm{m}^{3}$ & 17.9 & 17.9 & 17.9 & 17.9 & 17.9 & 17.9 \\
\hline Negative effect on the ecology & $10^{18} \mathrm{sej}$ & 5.20 & 5.55 & 5.73 & 8.00 & 7.10 & 7.08 \\
\hline
\end{tabular}

\subsection{Assessment of Social Effect of Urban Water System Connectivity Project in Xuchang}

\subsubsection{Flood Regulation Effect}

According to the flood control plan of river system in Xuchang and annual precipitation, the flood storage amount of Xuchang city water system connectivity project can be calculated. Based on Formula (9), the flood regulation effect can be calculated (Table 5). 
Table 5

Calculation results of flood regulation effect of project in Xuchang

\begin{tabular}{|llllllll|}
\hline Items & Units & $\mathbf{2 0 1 0}$ & $\mathbf{2 0 1 1}$ & $\mathbf{2 0 1 2}$ & $\mathbf{2 0 1 6}$ & $\mathbf{2 0 1 7}$ & $\mathbf{2 0 1 8}$ \\
\hline Flood storage capacity & $10^{4} \mathrm{~m}^{3}$ & 763.62 & 705.13 & 466.46 & 719.43 & 848.33 & 587.80 \\
\hline Solar transformity of surface water body & $10^{11} \mathrm{sej} / \mathrm{m}^{3}$ & 5.93 & 5.93 & 5.93 & 5.93 & 5.93 & 5.93 \\
\hline Flood regulation effect & $10^{18} \mathrm{sej}$ & 4.53 & 4.18 & 2.77 & 4.27 & 5.03 & 3.49 \\
\hline
\end{tabular}

\subsubsection{Landscape and Recreation Effect}

According to National Agricultural Product Cost-Income Data Compilation (Xu and Ding 2010-2012,2016-2018), the landscape and recreation value of water body per unit area in Xuchang was obtained by using equivalent factor method. Based on Formula (10), the landscape and recreation effect can be calculated (Table 6).

Table 6

Calculation results of landscape and recreation effect of project in Xuchang

\begin{tabular}{|llllllll|}
\hline Items & Units & $\mathbf{2 0 1 0}$ & $\mathbf{2 0 1 1}$ & $\mathbf{2 0 1 2}$ & $\mathbf{2 0 1 6}$ & $\mathbf{2 0 1 7}$ & $\mathbf{2 0 1 8}$ \\
\hline Landscape and recreation value per unit area & $10^{4} ¥ / \mathrm{hm}^{2}$ & 1.20 & 1.25 & 1.33 & 1.20 & 1.23 & 1.23 \\
\hline EDR & $10^{11} \mathrm{sej} / ¥$ & 1.67 & 1.67 & 1.67 & 1.67 & 1.67 & 1.67 \\
\hline Landscape and recreation effect & $10^{18} \mathrm{sej}$ & 1.48 & 1.54 & 1.64 & 1.73 & 1.78 & 1.77 \\
\hline
\end{tabular}

\subsubsection{Scientific Research Effect}

According to literature data retrieval, the number of relevant literatures was shown in Table 7, which was calculated by 6 pages per paper. Based on Formula (11), the scientific research effect was calculated (Table 7).

Table 7

Calculation results of scientific research effect of project in Xuchang

\begin{tabular}{|llllllll|}
\hline Items & Units & $\mathbf{2 0 1 0}$ & $\mathbf{2 0 1 1}$ & $\mathbf{2 0 1 2}$ & $\mathbf{2 0 1 6}$ & $\mathbf{2 0 1 7}$ & $\mathbf{2 0 1 8}$ \\
\hline Pages & page & 6 & 0 & 6 & 78 & 78 & 60 \\
\hline Solar transformity of research & $10^{15}$ sej/page & 3.39 & 3.39 & 3.39 & 3.39 & 3.39 & 3.39 \\
\hline Scientific research effect & $10^{17}$ sej & 0.20 & 0 & 0.20 & 2.64 & 2.64 & 2.03 \\
\hline
\end{tabular}

\subsection{Assessment of Economic Effect of Urban Water System Connectivity Project in Xuchang}

\subsubsection{Land Value Increment}

The project is located in Weidu District and Jian'an District. Land value increment is mainly reflected in the area of housing sales. Based on Formula (12), the land value increment effect was calculated (Table 8). 
Table 8

Calculation results of land value increment effect of project in Xuchang

\begin{tabular}{|llllllll|}
\hline Items & Units & $\mathbf{2 0 1 0}$ & $\mathbf{2 0 1 1}$ & $\mathbf{2 0 1 2}$ & $\mathbf{2 0 1 6}$ & $\mathbf{2 0 1 7}$ & $\mathbf{2 0 1 8}$ \\
\hline Increment of sales & $10^{8} ¥$ & 1.07 & 3.50 & 0.82 & 10.57 & 7.84 & 18.81 \\
\hline Ratio & $\%$ & 31.43 & 31.43 & 31.43 & 31.43 & 31.43 & 31.43 \\
\hline EDR & $10^{11} \mathrm{sej} ¥$ & 1.67 & 1.67 & 1.67 & 1.67 & 1.67 & 1.67 \\
\hline Land value increment & $10^{18}$ sej & 5.59 & 18.32 & 4.28 & 55.35 & 41.06 & 98.56 \\
\hline
\end{tabular}

\subsubsection{Negative Effect of Maintenance}

In order to ensure the normal operation and management of the water system, there are management and maintenance expenses every year. Based on Formula (13), the negative effect of maintenance was calculated (Table 9).

Table 9

Calculation results of negative effect of maintenance of project in Xuchang

\begin{tabular}{|llllllll|}
\hline Items & Units & $\mathbf{2 0 1 0}$ & $\mathbf{2 0 1 1}$ & $\mathbf{2 0 1 2}$ & $\mathbf{2 0 1 6}$ & $\mathbf{2 0 1 7}$ & $\mathbf{2 0 1 8}$ \\
\hline Maintenance expenses & $10^{6} ¥$ & 2.00 & 2.57 & 3.73 & 5.25 & 5.27 & 5.60 \\
\hline EDR & $10^{11} \mathrm{sej} / ¥$ & 1.67 & 1.67 & 1.67 & 1.67 & 1.67 & 1.67 \\
\hline Negative effect of maintenance & $10^{17} \mathrm{sej}$ & 3.34 & 4.28 & 6.21 & 8.75 & 8.78 & 9.34 \\
\hline
\end{tabular}

\subsection{Results and Analysis}

The project is located in the plain. Because of the small difference of terrain and the small amount of sediment, the effect of sediment transport was not calculated here. According to the above calculation results, the average effects of 20102012 and 2016-2018 were respectively used as the effects before and after the completion of the project. According to formula (2), the eco-economic effect of water system connectivity project in Xuchang was obtained (Table 10).

Table 10

Assessment table of eco-economic effects of project in Xuchang

\begin{tabular}{|c|c|c|c|c|c|c|c|c|c|c|c|}
\hline \multirow[t]{2}{*}{ Items } & \multicolumn{9}{|c|}{ emergy of effect $\left(\times 10^{18}\right.$ sej $)$} & \multirow{2}{*}{$\begin{array}{l}\text { EDR } \\
\text { (sej/\$) }\end{array}$} & \multirow{2}{*}{$\begin{array}{l}\text { Project } \\
\text { effect }\left(10^{6} \$\right)\end{array}$} \\
\hline & 2010 & 2011 & 2012 & $\mathrm{EM}_{1}$ & 2016 & 2017 & 2018 & $\mathrm{EM}_{2}$ & EM & & \\
\hline $\begin{array}{l}\text { Ecological } \\
\text { effect }\end{array}$ & 16.90 & 19.65 & 19.27 & 18.60 & 25.02 & 24.78 & 24.21 & 24.67 & 6.07 & \multirow{4}{*}{$\begin{array}{l}1.07 \\
\times 10^{12}\end{array}$} & 5.65 \\
\hline $\begin{array}{l}\text { Social } \\
\text { effect }\end{array}$ & 6.03 & 5.72 & 4.43 & 5.39 & 6.26 & 7.07 & 5.46 & 6.27 & 0.87 & & 0.81 \\
\hline $\begin{array}{l}\text { Economic } \\
\text { effect }\end{array}$ & 5.25 & 17.89 & 3.66 & 8.93 & 54.48 & 40.18 & 97.62 & 64.09 & 55.16 & & 51.35 \\
\hline $\begin{array}{l}\text { Eco- } \\
\text { economic } \\
\text { effect }\end{array}$ & 28.17 & 43.26 & 27.35 & 32.93 & 85.76 & 72.03 & 127.29 & 95.03 & 62.10 & & 57.81 \\
\hline
\end{tabular}

(1) According to Table 10, the average effect of Xuchang urban water system connectivity project is 57.8 million dollars/year. The project was constructed with an investment of 37.3 million dollars/year. The cost-benefit ratio is 1.55 , indicating that the project is feasible. The project has produced a huge eco-economic effect, and has made contributions to the economic growth of the area, the improvement of residents' material and spiritual enjoyment, and the improvement of the ecological environment. Lee and Jung (2015) calculated the ecological benefits of the Cheonggyecheon Urban River 
Restoration Project in Seoul, South Korea, and calculated that the project benefit-to-cost ratio is 0.75 . It showed that the evaluation of project benefits should not only include the ecological benefits. Economic and social benefits are equally important. Otherwise, it will get the false impression that the project is not feasible.

(2) Based on Table 5, among the eco-economic effects of the project, the economic effect accounts for the largest proportion, accounting for $88.83 \%$ of the total effect. This is mainly due to the large land value increment effect. It showed that the project makes the surrounding land more valuable. Liang et al. (2010) evaluated the comprehensive benefits of the transformation and restoration project of urban river and concluded that the surrounding land appreciation benefits accounted for $95.75 \%$ of the total benefits. It can be concluded that a good water environment can indeed promote the development of the surrounding economy and have a non-negligible impact on all industries. The proportion of engineering ecological effect is $9.77 \%$. It showed that the impact of the project on the ecological environment in this area cannot be ignored, and it is necessary to adopt scientific methods to quantify. The ecological and social effects are far lower than the economic effect, which indicated that the water system connectivity project, as an urban ecosystem, has a far greater impact on the economy than other impacts due to the large human disturbance factors.

(3) According to Fig. 4 and Fig. 5, among the ecological effects of project, the effect of biodiversity conservation is the highest, which is $6.83 \times 10^{18}$ sej. It showed that this project can provide a good place for energy flow and material exchange among species. Holgado et al. (2020) studied the urban water system under four different circumstances, and found that all of them had a good effect on biodiversity conservation, which is consistent with the results of this paper. In addition, the negative effect on the ecology cannot be ignored, which is $1.90 \times 10^{18}$ sej. Therefore, it is necessary to transform urban channelized rivers into near-natural rivers. The social effect is the smallest in eco-economic effects, accounting for only $1.40 \%$. In the social effect, the flood regulation effect is the largest, which indicated that the project has flood control and drainage function, and provides security for the safety of residents' lives and property. In the economic effect, the cost of management and maintenance increases, which is reasonable because the construction of the project leads to the increase of human and material resources input.

\section{Conclusions}

As an urban eco-hydraulic project, the urban water system connectivity project can not only regulate climate, protect biodiversity, transport sediment, purify water quality, but also have the effects of flood regulation, landscape and recreation, scientific research and land value increment. However, if the project is not reasonably developed, managed and maintained, it will have negative effect. Therefore, the scientific assessment of the project is conducive to a comprehensive understanding of its ecological, social and economic effects, and provides data support for the sustainable development, research and protection of the project. Based on emergy theory, this paper analyzed the construction and evaluation methods of eco-economic effects of the project, and took Xuchang urban water system connectivity project as an example to evaluate. The results showed that the average effect after the completion of the project is 57.8 million dollars/year, which has brought huge effect for the urban ecological construction and economic and social development of Xuchang. However, since the Xuchang Project was completed at the end of 2015, there are only three years of data available for research so far, so the trend of effect change cannot be analyzed yet. In addition, most of the solar transformities are based on the previous results, and the solar transformity of Xuchang City need to be studied further.

\section{Declarations}

Ethical Approval Informed consent.

Consent to Participate Informed consent.

Consent to Publish Informed consent.

Page $12 / 18$ 
Competing interests The authors have no relevant financial or non-financial interests to disclose.

Authors Contributions All authors contributed to the study conception and design. Conceptualization: Cuimei Lv; Methodology: Cuimei Lv and Huali Liao; Formal analysis and investigation: Minhua Ling; Writing - original draft preparation: Cuimei Lv and Huali Liao; Writing - review and editing: Cuimei Lv, Huali Liao, Zening Wu and Denghua Yan; Funding acquisition: Minhua Ling; Resources: Denghua Yan; Supervision: Minhua Ling and Zening Wu. All authors have read and agreed to the published version of the manuscript.

Funding This research was funded by the National Natural Science Foundation of China (No.NSCF-52079125).

Availability of data and materials All data and materials support our published claims and comply with field standards.

\section{References}

1. Anderson ST, West SE (2006) Open space, residential property values, and spatial context. Reg Sci Urban Econ $36: 773-789$

2. Asakawa S, Yoshida K, Yabe K (2004) Perceptions of urban stream corridors within the greenway system of Sapporo, Japan. Landscape and Urban Planning 68:167-182

3. Brander LM, Koetse MJ (2011) The value of urban open space: meta-analyses of contingent valuation and hedonic pricing results. J Environ Manage 92:2763-2773

4. Carey RO, Migliaccio KW, Brown MT (2011) Nutrient discharges to Biscayne Bay, Florida: trends, loads, and a pollutant index. Sci Total Environ 409:530-539

5. Chen B (2016) Study on the influence of urban water system management on the land price of the surrounding housing. Dissertation, Xi'an University of Technology

6. Cui G, Chen X, Xiang L, Zhang Q, Xu Q (2017) Evaluation of water environment improvement by interconnected river network in plain area. JHydraulic Eng 48:1429-1437

7. Everard M, Shuker L, Gurnell A (2011) The Mayes Brook restoration in Mayesbrook Park, East London:an ecosystem services assessment.Environment Agency

8. Grizzetti B, Lanzanova D, Liquete C, Reynaud A, Cardoso AC (2016) Assessing water ecosystem services for water resource management. Environ Sci Policy 61:194-203

9. Hao M (2018) Preliminary Aquatic Life Criteria Development of Ammonia in Qingyi River Basin. Dissertation, Zhengzhou University

10. Holgado PM, Jendrzyczkowski Rieth L, Berrocal Menárguez A-B, Allende Álvarez F (2020) The Analysis of Urban Fluvial Landscapes in the Centre of Spain, Their Characterization, Values and Interventions. Sustainability 12. doi:10.3390/su12114661

11. HSB (2010) -2012,2016-2018) The statistical yearbook of Henan Province.China Statistics Press

12. HWCB (2010-2012,2016-2018) The water resources bulletin of Henan Province. http://slthenangovcn/

13. Lan S, Qin P, Lu H (2002) Emergy analysis of ecological-economic system. Chemical Industry Press

14. Lee M, Jung I (2015) Assessment of an urban stream restoration project by cost-benefit analysis: The case of Cheonggyecheon stream in Seoul, South Korea. KSCE J Civ Eng 20:152-162

15. Liang J, Qi Y, Cao D (2010) A Study on the Comprehensive Benefit Assessment Framework of Urban River Restoration Projects.Modern Urban Research25:63-69

16. Liu G, Casazza M, Hao Y, Zhang Y, Ulgiati S (2019) Emergy analysis of urban domestic water metabolism: A case study in Beijing (China). J Clean Prod 234:714-724

Page $13 / 18$ 
17. Lv C (2009) Research on Ecological Economic Value of Regional Water Resources Based on Emergy Theory. Dissertation, Zhengzhou University

18. Lv C, Li H, Ling M, Guo X, Wu Z, Gu C, Li Y (2021) An Innovative Emergy Quantification Method for Eco-economic Compensation for Agricultural Water Rights Trading. Water Resour Manage 35:775-792

19. Martínez-Paz J, Pellicer-Martínez F, Colino J (2014) A probabilistic approach for the socioeconomic assessment of urban river rehabilitation projects. Land Use Policy 36:468-477

20. Meillaud F, Gay JB, Brown MT (2005) Evaluation of a building using the emergy method. Sol Energy 79:204-212

21. Mourato S, Atkinson G, Ozdemiroglu E, Newcombe J, de Garis Y (2005) Does a Cleaner Thames Pass an Economic Appraisal? Water Int 30:174-183

22. Odum HT (1996) Environment Accounting: Emergy and Environment Decision Making. John Wiley

23. Olaj A, Gabrijelčič P, Fikfak A (2012) Urban riverside public space - river as the generator of development Geodetski vestnik. 56:151-168. doi

24. Park K, Kim D, Lee M, Choi C (2017) Analysis of micro-climate on the programs of urban infrastructure regeneration in $\mathrm{J}$ city, Republic of Korea. Urban Forestry \& Urban Greening 27:43-49

25. Steinhorst J, Klöckner CA, Matthies E (2015) Saving electricity - For the money or the environment? Risks of limiting pro-environmental spillover when using monetary framing. J Environ Psychol 43:125-135

26. Sun J, Yuan X, Liu G, Tian K (2019) Emergy and eco-exergy evaluation of wetland restoration based on the construction of a wetland landscape in the northwest Yunnan Plateau, China. J Environ Manage 252:109499

27. Wang F, Wang CM, Wang Q (2011) Research on the Jing-Wei River System's Ecological Corridor in Metropolitan Area of Xi'an. Adv Mater Res 250-253:3367-3371

28. Wen T, Xie F, Yan Y (2005) Emergy Evaluation of Wild Terrestrial Vertebrate Animal Resource in West of China Sichuan Journal of Zoology:40-41+45

29. Wu A, Che Y, Yang K, Zhao J (2005) Method for post evaluation of urban river regulation and case study. JHydraulic Eng 09:1088-1093

30. Wu Z, Di D, Wang H, Wu M, He C (2019) Analysis and emergy assessment of the eco-environmental benefits of rivers.Ecological Indicators106. doi:10.1016/j.ecolind.2019.105472

31. Xie G, Lu C, Leng Y, Zheng D, Li S (2003) Ecological assets valuation of the Tibetan Plateau.Journal of natural resources:189-196

32. Xie G, Zhang C, Zhang L (2015) Improvement of the Evaluation Method for Ecosystem Service Value Based on Per Unit Area. Journal of natural resources 30:1243-1254

33. XSB (2010) -2012,2016-2018) Xuchang citynational economy and social development statistics bulletin

34. Xu L, Ding X (2010-2012,2016-2018) National Agricultural Product Cost-Income Data Compilation China Statistics Press

35. Xue F, Luo K, Li Y, Dang A, Zhang Y (2018) Ecosystem Service Value Assessment of Urban Water Corridor Based on Chinese GF-2 Remote Sensing Data: A Case Study of Beijing Center Area.Chinese Landscape Architecture34:50-54

36. Yan J, Li N (2010) Water network connection project of Donghu Lake in Wuhan City. Yangtze River 41:82-84

37. Zhang H, Feng M, Wang L, Lie W (2015) Research on Water Environmental Effects of Qingyi River Based on Ecological Water Diversion.Journal of Xi'an University of Technology31. doi:10.19322/j.cnki.issn.1006-4710.2015.01.015

38. Zhang K (2017) The ecosystem service function evaluation of city drainage in Zhengzhou. Dissertation, Zhengzhou University

\section{Figures}




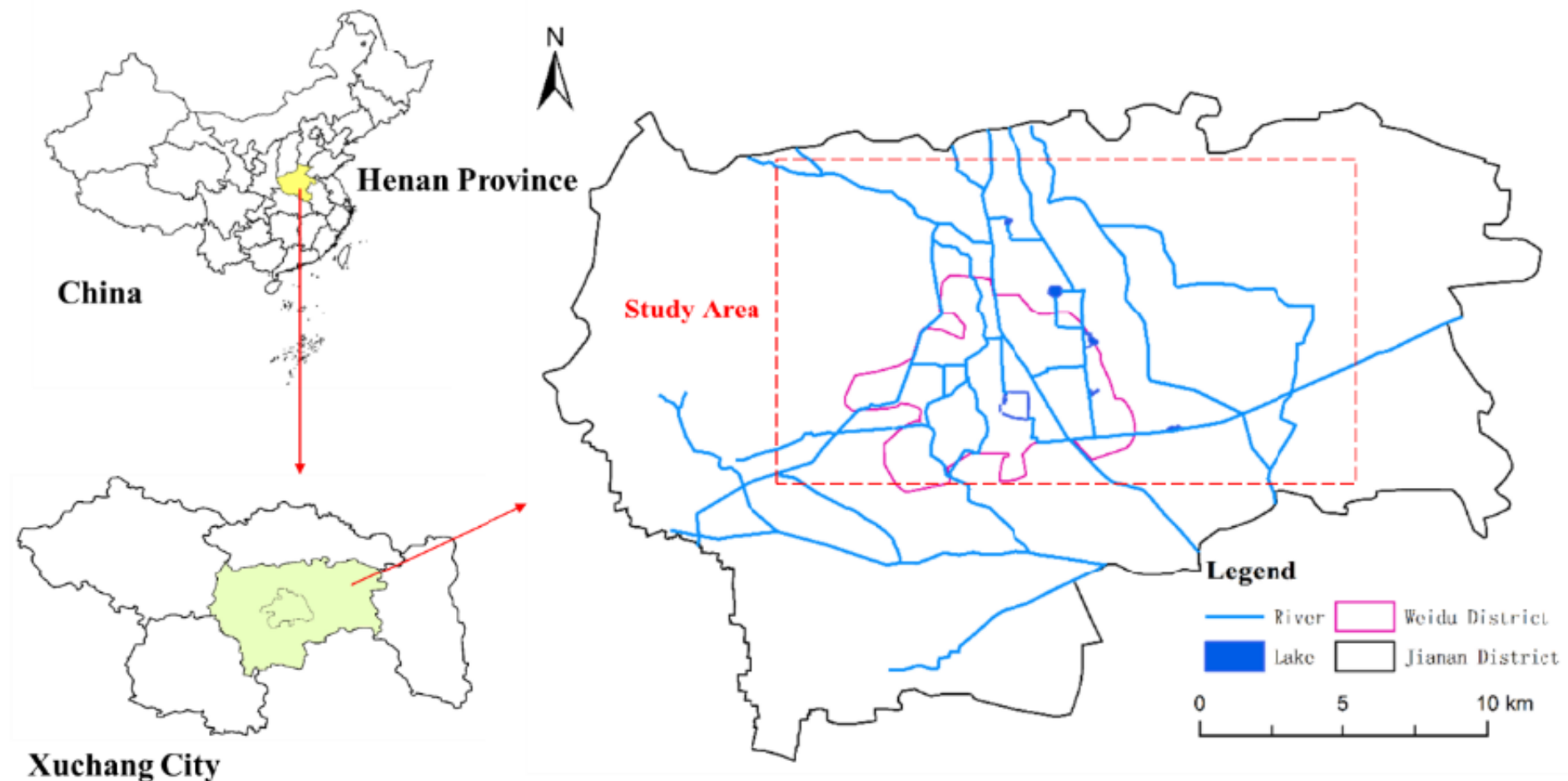

Figure 1

The location of Xuchang water system connectivity project.

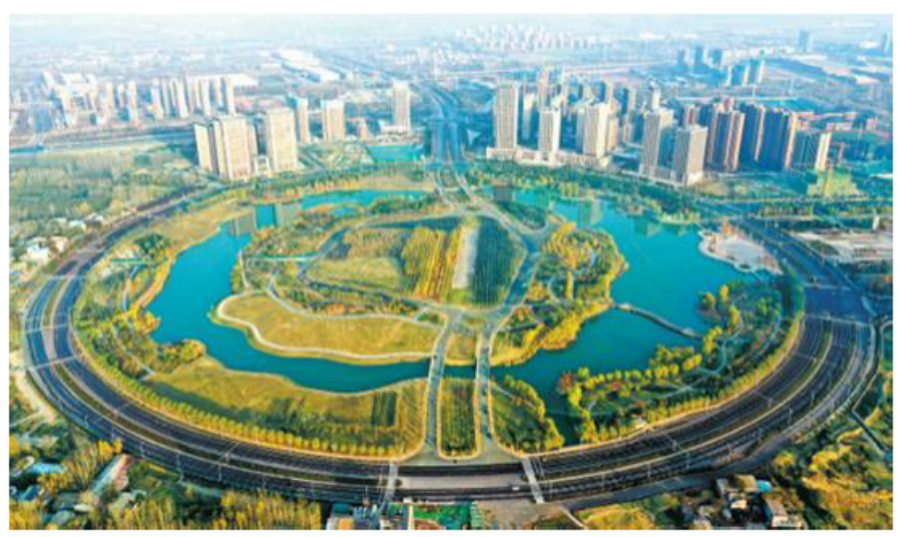

(a)

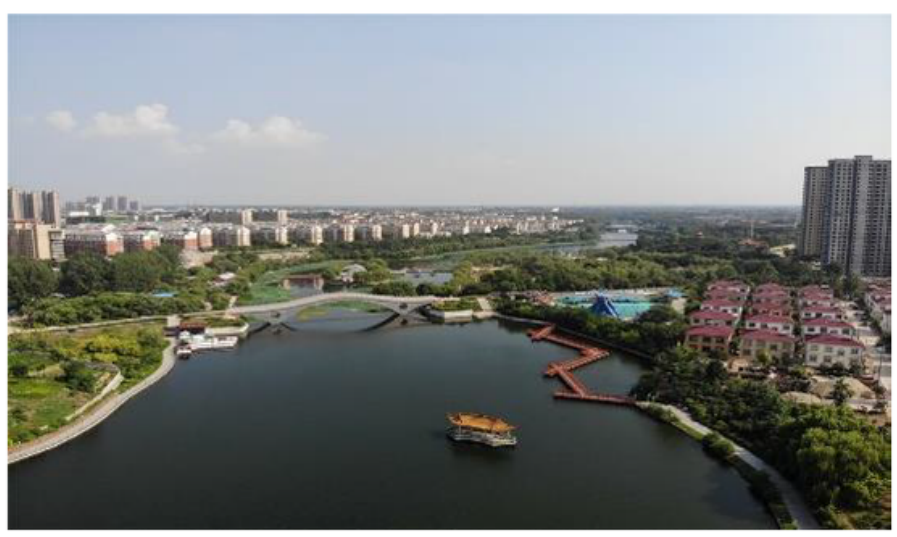

(b)

Figure 2

(a) Furong Lake; (b) Qingni River. 


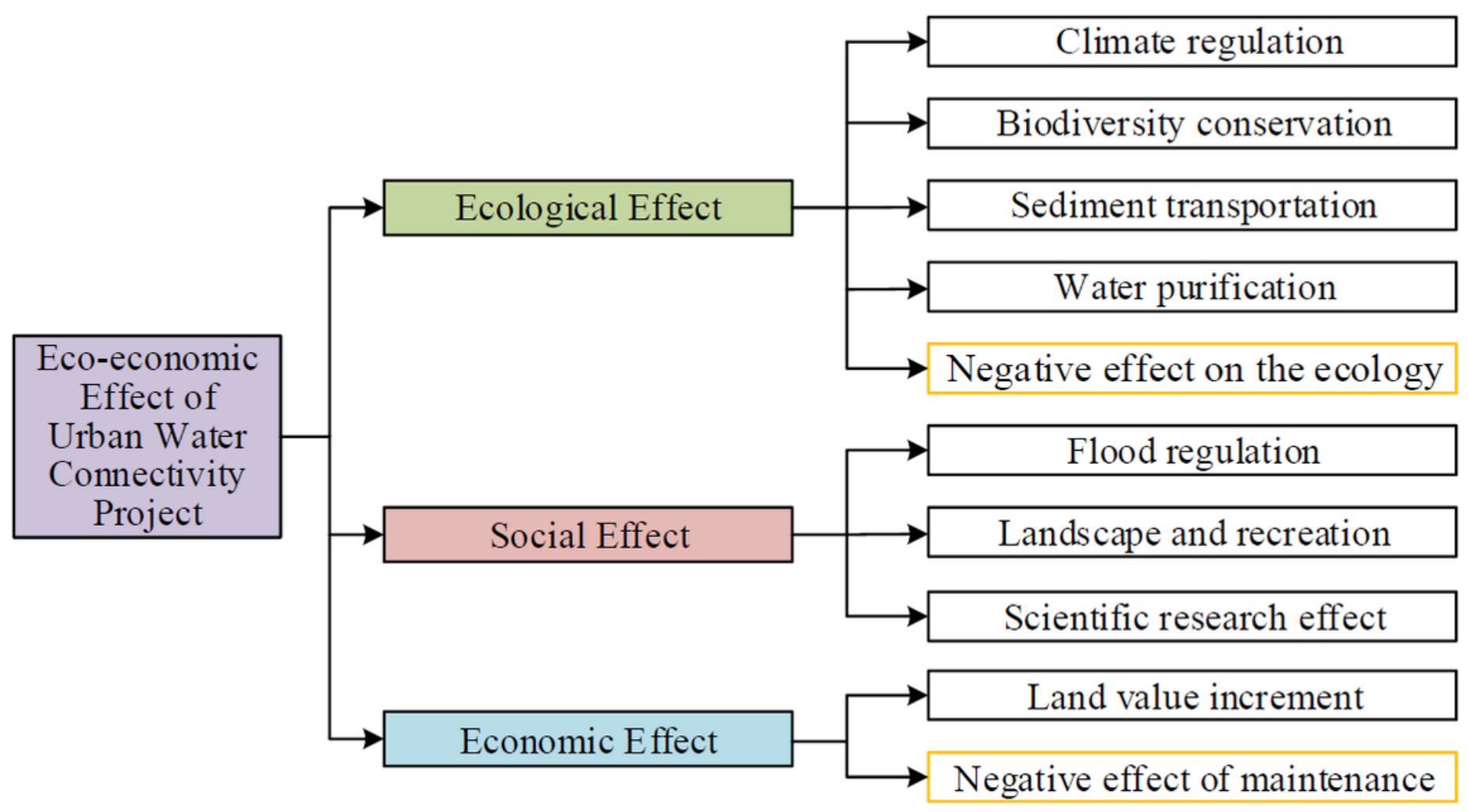

Figure 3

Eco-economic effect composition system chart of urban water system connectivity project. 


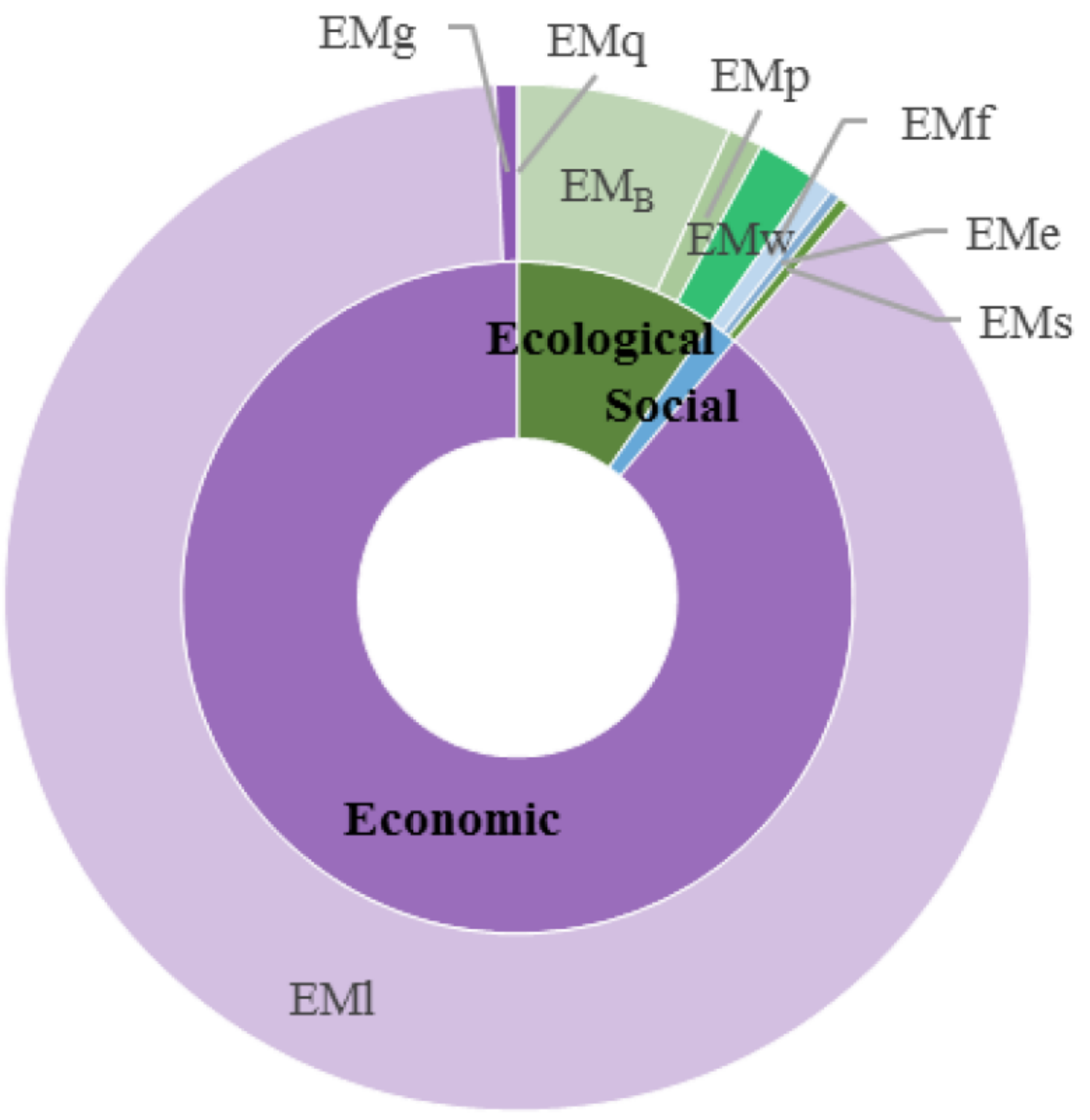

Figure 4

Effect ratio plot. 


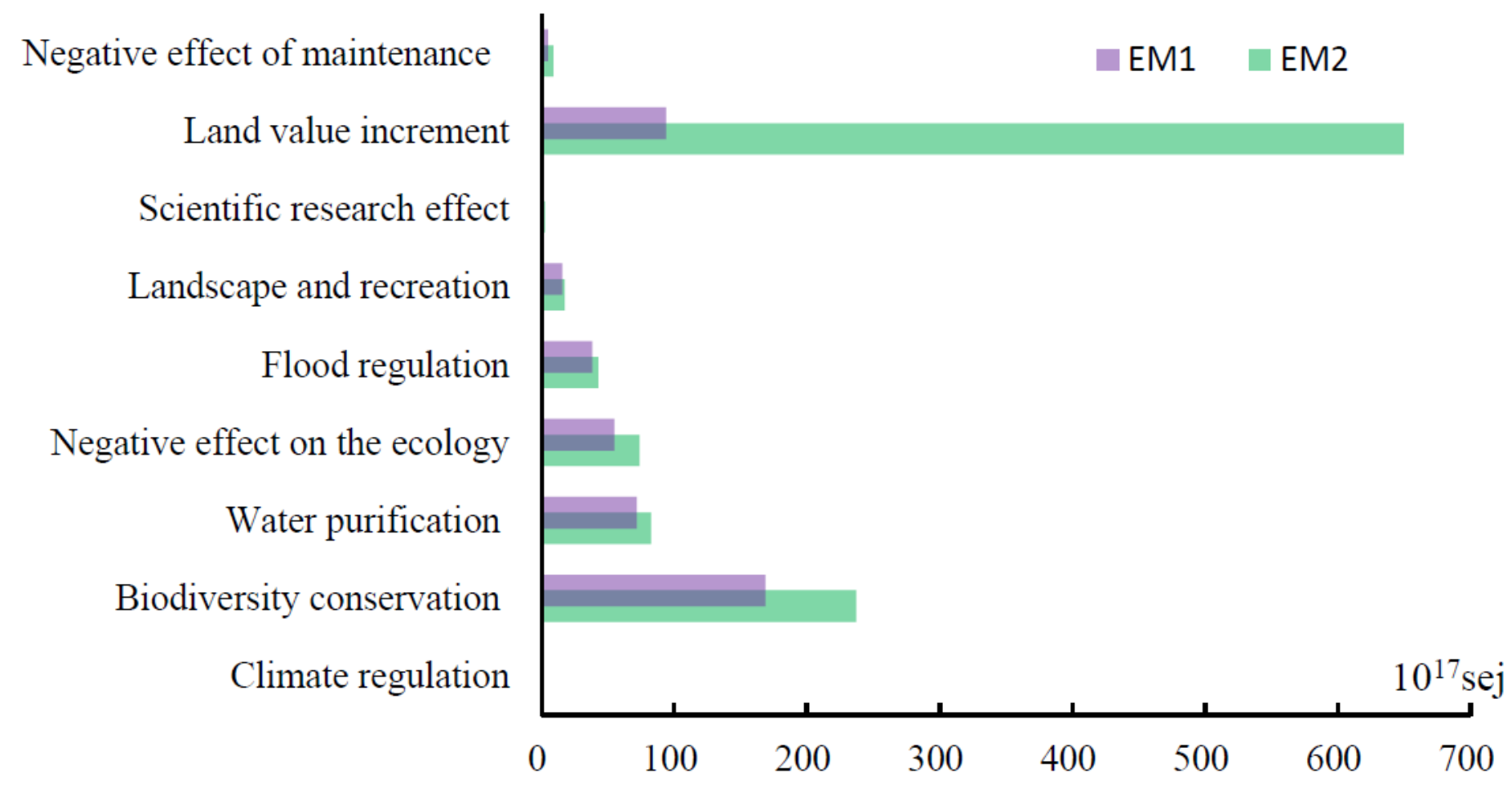

Figure 5

Effect changes before and after completion of the project. 